\title{
No-Fault Divorce and the Compression of Marriage Ages
}

\author{
Douglas W. Allen \\ Simon Fraser University \\ Krishna Pendakur \\ Simon Fraser University \\ Wing Suen* \\ Chinese University of Hong Kong
}

September, 2005

\begin{abstract}
We examine the impact of the introduction of no-fault divorce law on the behavior of never-married people. In particular, we evaluate how it affects an indicator of marital search intensity, the age at first marriage, in the context of a model where everyone has a different value of marriage. The heterogeneity of individual values implies that the legal change affects different people differently. In particular, no-fault divorce has an ambiguous effect on average marital search intensity, but an unambiguously negative effect on the variance of search intensity. We test this hypothesis with a large data set of American marriage records from 1970 to 1995. We find support for our prediction. Controlling for state-level heterogeneity and for time trends, the standard deviation of the log age at first marriage drops by approximately five percent with the introduction of no-fault divorce. Given our model, the mean age of first marriage is an indicator of welfare over the transition. We find that the mean age at first marriage increases slightly, suggesting that the mean person is slightly worse off with no-fault divorce.
\end{abstract}

* Communications to Doug Allen: email allen@sfu.ca. Thanks to Peg Brinig, Ken Kasa, Clyde Reed, and to seminar participants at Montana State, George Mason, and Western Washington Universities for their comments. 


\section{Introduction}

The no-fault divorce revolution that took place in the United States over the past three decades provides an opportunity to test economic models of marital behavior. To date, most research on no-fault laws has focused on the effect it had on the divorce rate. Although there is still some contention over this outcome, most agree that the change in law did contribute to a rise in the divorce rate. ${ }^{1}$ However, nofault divorce laws should affect marriage behavior beyond the incentive to divorce. For example, easier divorce should have an impact on incentives for marital search and therefore on the age at which individuals get married. ${ }^{2}$

People value marriage. By this, we mean that people value a broad spectrum of marriage features, including its nature as a promise, its long term and permanent commitment to children and other people, and its connection with personal happiness. However, not all people value marriage identically. A person's valuation of marriage will affect, even determine, their tolerance for a mismatched partner, and therefore will condition their marital search behavior. Because everyone is different to some extent in terms of the value they place on marriage, any movement towards easy divorce will have different individual effects. For individuals who value marriage and its permanence greatly, easy divorce makes marriage less permanent, and thus makes marital search more protracted. On the other hand, for individuals who

1 No-fault divorce refers to legislation that removed fault provisions from the grounds for divorce or added "no-fault" grounds to existing fault grounds. The important change was that divorce moved from being essentially a mutual decision between the husband and wife to a unilateral one on the part of the spouse most wanting a divorce. Allen (1999) provides a complete literature review on the no-fault divorce debate. In brief there have been 19 studies, with 11 arguing that the divorce rate increased. Most of the studies arguing for no effect were done early on and many made mistakes in classifying the state laws. Since 1986, only one study has argued that no-fault laws made no statistical difference to divorce rates. A recent study by Wolfers (2003) also finds that liberalized divorce laws caused a discernable rise in divorce rates for about a decade. Our result depends on divorce becoming easier with the introduction of no-fault. Our result does not require an increase in the divorce rate.

2 The effect of no-fault on marriage age is but one additional effect. The law should also impact labor force participation, fertility, and other social and human capital decisions. See Parkman (1998) for a further discussion. 
value marriage and its permanence less, an easy exit option makes marriage more attractive and marital search easier and quicker.

Given an individual's preferences, therefore, the divorce law will condition their search behavior and marriage age. Under a fault divorce regime those who value marriage greatly will marry young because the difficulty in divorcing protects their interests and expands the set of acceptable matches. When the law switches to nofault divorce they now must search harder and longer to ensure a more compatible spouse - in effect, search substitutes for the prior legal restrictions on divorce. Thus, these individuals experience an increase in their marriage age after the switch to no-fault.

The opposite is the case for those who value marriage less. Under a fault law, these people searched longer because they were more concerned about mistakes in matching. With a switch to no-fault divorce, these individuals risk being less selective in the choice of spouse because a bad choice can be offset by a relatively easy divorce. The willingness to be less selective means these people have a reduction in their marriage age after the change in the law.

Given the divorce law, differences in marriage preferences condition individual search, and therefore, the distribution of marriage ages. Under fault divorce, those who value marriage greatly marry younger and those who value marriage less marry older. This, when combined with the changes in search behavior mentioned above, means that those who would have married older marry a little sooner with the introduction of no-fault divorce, and those who would have married younger marry a little later with the introduction of no-fault divorce. The result is that with the change in divorce law there is a compression in the spread of marriage ages.

In contrast, simply looking at the mean age at marriage prior to and after the adoption of no-fault divorce might show a relatively small effect since the different types of people will tend to offset each other. Therefore, a small change in the mean age at marriage might mask large offsetting changes at the individual level. The 
objective of this paper is to investigate the possibility of large micro level changes in the age at marriage of individuals by looking at what happens to the spread of marriage ages as divorce laws change.

Our main prediction, that the spread of the marriage age distribution should decline with the introduction of no-fault divorce, is broadly corroborated by the data. Controlling for state-specific effects on the age at first-marriage distribution and for national-level trends over time, we find that the introduction of no-fault divorce is associated with a $1 \%$ to $5 \%$ decrease in the standard deviation of the log of age at first marriage. This finding is robust to various measures of the spread of the marriage age distribution and is seen for both men and women. Under the model, the average age at first marriage is a rough indicator of the welfare effect of the legal change. Those who search more and marry later under no-fault are worse off, and those who search less and marry earlier are better off. Controlling for statespecific effects and for national-level trends, we find a small increase of about $0.3 \%$ to $0.7 \%$ in the age at first marriage. Given average ages at first marriage of 25 , this suggests that no-fault divorce is associated with 1 to 2 months more marital search with an associated small loss in welfare.

\section{The Model}

Suppose that both men and women in a marriage market can be described by a sufficient statistic: $\theta \in[0,1]$. The larger is $\theta$, the more the person values marriage. People with high $\theta$ might have very strong feelings about the religious value of marriage, its nature as a promise, the well-being (material or otherwise) of children they may have in the future, or other things relating to the permanence of marriage.

Naturally people with higher $\theta$ tend to derive greater benefits from marriage than from staying single. Other things equal, a person's utility from marriage is increasing in $\theta$ if the marriage is kept intact. The utility from marriage also depends on how compatible the couple are in their attitudes toward marriage. People with 
different values of $\theta$ will make different life-style choices, which tends to reduce the gains from marriage. We therefore assume that the utility from marriage is decreasing in the distance between the couple's types. In particular, this assumption suggests that a person with a high $\theta$ is not necessarily a more desirable marital partner for someone with a low $\theta .^{3}$

We assume that a married woman, because of circumstance or changes in tastes, prefers a divorce with probability $1-p_{f}$. Similarly but independently, a married man may experience a marital shock and prefer to leave the union with probability $1-p_{m} \cdot{ }^{4}$ Because high- $\theta$ types place a greater value on the permanence of marriage, we assume that the cost of divorce when it happens is also greater for these types, even if they initiate the separation. ${ }^{5}$ For a woman of type $\theta_{f}$, her payoffs when married to a man of type $\theta_{m}$ will depend on the realization of marital shocks. We display these payoffs in the matrix in Table $1 .{ }^{6}$ It is assumed that husband and wife will stay married if neither of them experiences a marital shock. The woman's utility in this state is $k \theta_{f}+1-\left(\theta_{f}-\theta_{m}\right)^{2}$. The constant $k$ is positive and greater than 2 to ensure that wife's utility is increasing in her type if both partners prefer to stay in the marriage. If both partners experience marital shocks, divorce is the outcome and the woman's utility in such a state is $1-\theta_{f}$, which is decreasing in her type. If one of the couple prefers a divorce while the other prefers to stay in the marriage, the actual outcome will depend on the legal regime and the corresponding payoffs are as shown in Table 1.

Although this payoff matrix is stylized, it is constructed to match the assumptions about types and marital shocks as well as the facts found in the marriage

3 For example, while a high- $\theta$ man may be very committed to his family, he may also expect his wife to be equally committed. Women with high values of $\theta$ may not mind (or even welcome) such expectations, but women with low values of $\theta$ may find these expectations burdensome.

4 We assume that these marital shocks occur for exogenous reasons, regardless of type, in order to focus the model on the question at hand. Along the same lines, we assume that the change in legal regime is also exogenous.

5 The fact that these people prefer a divorce only means that the are dissatisfied with their current partner; it does not mean that they no longer place great value on marriage as an institution.

6 We model the woman's choice problem, but the man's is completely symmetrical. 


\section{Table 1}

\section{Marriage and Divorce Payoffs to Woman under Different States}

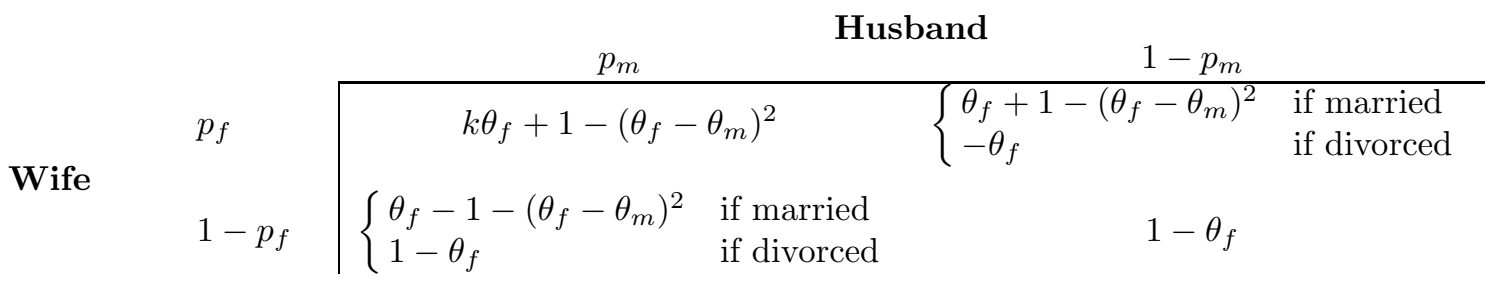

matching literature. First, men and women are complementary in types and engage in assortive matching. ${ }^{7}$ That is, likes tend to marry likes, and mismatches are costly for all types of people. Second, all marriage payoffs are increasing in $\theta_{f}$, and all divorce payoffs are decreasing in $\theta_{f}$. Hence $\theta_{f}$ denotes a preference for the permanence of marriage. Third, even when the marriage stays intact, the utility from marriage depends on marital shocks. A husband who has a marital shock and prefers to (but does not) leave the union brings less utility to his wife (i.e., $k \theta_{f}>\theta_{f}$ ). And when it is the woman who experiences the marital shock, her utility from marriage is even lower (i.e., $\left.\theta_{f}-1<\theta_{f}+1\right)$. Third, the wife prefers marriage when the payoff to marriage is higher than divorce $\left(\theta_{f}+1-\left(\theta_{f}-\theta_{m}\right)^{2}>-\theta_{f}\right)$, and she prefers divorce when the payoff is higher divorced than married $\left(1-\theta_{f}>\theta_{f}-1-\left(\theta_{f}-\theta_{m}\right)^{2}\right)$. Finally, the divorce payoff is higher for the woman if it is she, rather than her husband, who experiences the marital shock $\left(1-\theta_{f}>-\theta_{f}\right)$.

The expected utility of marriage depends on the legal regime. With fault law, divorce must be mutually agreed upon. With no-fault law, divorce can take place unilaterally. In the beginning, we assume that side payments between the wife and husband are impossible, so that the law affects the probability of a marriage being

7 This follows from the fact that the marriage payoff has positive cross partial derivative with respect to male and female types. 
permanent. Later on, we explain why introducing side payments does not alter our conclusion about search behavior in the marriage market.

Under fault law, marriage ends in a divorce if and only if both partners experience a marital shock. So, for a woman of type $\theta_{f}$, expected utility from marriage is:

$$
\begin{aligned}
E U^{f}(\text { fault })= & p_{f} p_{m}\left[k \theta_{f}+1-\left(\theta_{f}-\theta_{m}\right)^{2}\right]+p_{f}\left(1-p_{m}\right)\left[\theta_{f}+1-\left(\theta_{f}-\theta_{m}\right)^{2}\right]+ \\
& \left(1-p_{f}\right) p_{m}\left[\theta_{f}-1-\left(\theta_{f}-\theta_{m}\right)^{2}\right]+\left(1-p_{f}\right)\left(1-p_{m}\right)\left(1-\theta_{f}\right) .
\end{aligned}
$$

The expected utility from marriage of a woman is a quadratic function in her potential partner's type, $\theta_{m}$. Maximizing this expression with respect to $\theta_{m}$ shows that the optimal mate is of type $\theta_{m}^{*}=\theta_{f}$. This means that the best marriage consists of partners exactly like each other in terms of their type. When search is costly, however, the best is the enemy of the good. We assume a woman will marry as soon as she finds a man with type $\theta_{m}$ such that

$$
E U^{f}(\text { fault }) \geq E U^{f} \text { (single) } .
$$

The comparison is shown in Figure 1. The function $E U^{f}$ (fault) has an inverted Ushape and reaches a maximum at $\theta_{m}=\theta_{f}$. The function $E U^{f}$ (single) is independent of $\theta_{m}$ and is therefore depicted by a horizontal line. There is a range of male types $\left[\underline{\theta}_{m}, \bar{\theta}_{m}\right]$ such that inequality (2) holds. A woman of type $\theta_{f}$ will find males in this range acceptable as marriage partners.

Before proceeding with the case of no-fault divorce, it is important to emphasize that the range of acceptable mates is a function of the woman's type. The mathematical derivation of this result is in the Appendix, but the economic intuition is straight-forward. People who are more committed to marriage typically derive greater utility from marriage than do the less committed types. As long as the probability of marital breakup is not too high, therefore, the opportunity cost of remaining single is higher for the more committed types. Hence they tend to have 


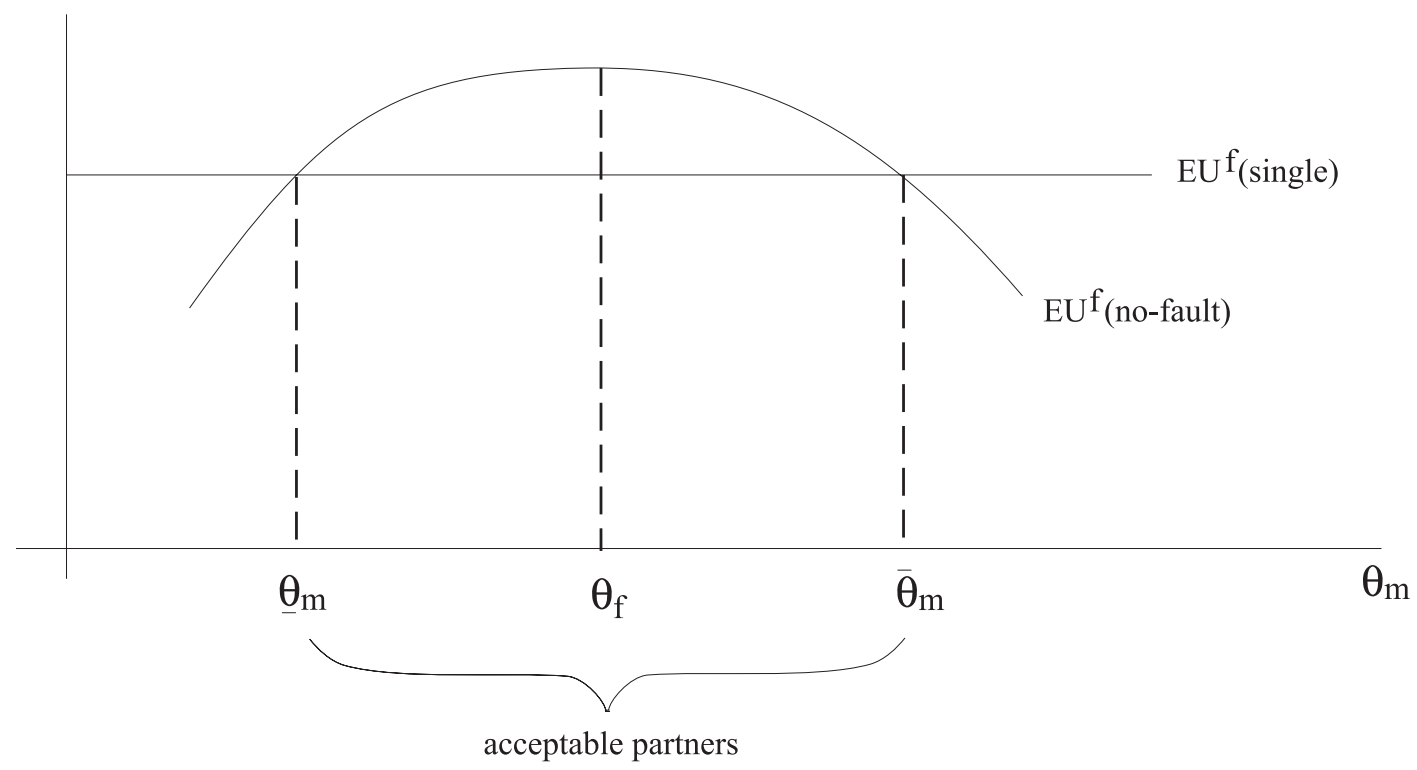

Figure 1

a larger set of acceptable mates. If we assume that the cost of marital search is similar for all types of people, then the high- $\theta$ types need to search less under fault than do the low- $\theta$ types and therefore marry younger. ${ }^{8}$

Consider how the situation changes under a no-fault regime. In this case, the couple stay married if and only if both prefer marriage to divorce. The expected utility from marriage for a woman of type $\theta_{f}$ is:

$$
E U^{f}(\text { no-fault })=p_{f} p_{m}\left[k \theta_{f}+1-\left(\theta_{f}-\theta_{m}\right)^{2}\right]-p_{f}\left(1-p_{m}\right) \theta_{f}+\left(1-p_{f}\right)\left(1-\theta_{f}\right) .
$$

Again, this is a quadratic function in $\theta_{m}$ and the optimal mate is $\theta_{m}^{*}=\theta_{f}$, but the range of acceptable partners under no-fault law is different from that under fault law. Taking the difference in expected utilities under the two regimes we obtain:

$$
\begin{aligned}
E U^{f}(\text { no-fault })-E U^{f}(\text { fault })= & p_{f}\left(1-p_{m}\right)\left[-2 \theta_{f}-1+\left(\theta_{f}-\theta_{m}\right)^{2}\right]+ \\
& \left(1-p_{f}\right) p_{m}\left[-2 \theta_{f}+2+\left(\theta_{f}-\theta_{m}\right)^{2}\right] .
\end{aligned}
$$

8 We have opted not to explicitly model the search process because the implication is rather straightforward. See, for example, Keeley (1977) for an explicit discussion of the optimal timing of marriage. In a more elaborate search model, one can define a value function $V^{f}\left(\theta_{m}\right)=$ $\max \left\{E U^{f}\left(\theta_{m}\right),-c+E\left[V^{f}(\cdot)\right]\right\}$, where $E U^{f}\left(\theta_{m}\right)$ is defined by equation (1) and $c$ is the search cost. Because $E U^{f}$ has an inverted U-shape, the optimal stopping region is an interval, and the duration of search is an increasing function of the measure of male types in that interval. 
This difference is decreasing in $\theta_{f}$. Furthermore, if

$$
4 p_{f}\left(1-p_{m}\right) \geq 2\left(1-p_{f}\right) p_{m} \geq p_{f}\left(1-p_{m}\right)
$$

then the difference is positive for $\theta_{f}=0$ and negative for $\theta_{f}=1$. It follows that there is a critical $\hat{\theta}_{f}$ such that those with $\theta_{f}<\hat{\theta}_{f}$ benefits from no-fault divorce while those with $\theta_{f}>\hat{\theta}_{f}$ are hurt by the change in law. No legal regime dominates for all $\theta_{f} \cdot{ }^{9}$

Figure 2 shows expected utility and acceptable matches under fault and no-fault. For women with $\theta_{f}<\hat{\theta}_{f}$ the transition from fault to no-fault divorce, with its easy exit provision, provides a larger expected utility from marriage. Since the expected utility from remaining single does not change, the span of acceptable partners expands. The opposite is the case where $\theta_{f}>\hat{\theta}_{f}$. For these high commitment types the transition lowers the expected utility from marriage, and the span of acceptable partners shrinks.

Under a fault regime, those who are more committed to marriage have a larger set of acceptable partners and they tend to marry younger than do the low-commitment types. With the switch to no-fault this effect weakens. Those who had high $\theta$ and married at a younger age $\left(\theta>\hat{\theta}_{f}\right)$ marry a little later, while those who had low $\theta$

9 It should be pointed out that allowing side payments at the time of divorce does not alter this conclusion. Allowing side payments results in all efficient divorces taking place and all efficient marriages remaining intact. However, our argument hinges on shifts in the EU function, which still occurs with side payments. For example, consider the case where the husband wants a divorce but the wife does not. Also suppose that this woman is a committed type so that the value of maintaining the marriage for her is higher than the benefits of divorce for her husband (an efficient marriage). Under fault law, the marriage stays intact as long as she objects to a divorce, and her expected utility from marriage is given by equation (1). Under a no-fault regime, the wife is able to pay a sufficiently high payment to preserve the marriage. Nevertheless, because of the side payment she has to pay, her expected utility is lower than $E U^{f}$ (fault). In other words, the assignment of property rights may not affect divorce outcomes under bargaining, but it does affect the allocation of income between husband and wife, and the level of expected utility. Essentially the switch to no-fault lowers EU for high- $\theta$ types either because (i) they are more likely to get divorced (without side payments), or (ii) they will have to pay to remain married (with side payments). Therefore, our conclusion that the introduction of no-fault divorce lowers the expected utility of high- $\theta$ types and raises the expected utility of low- $\theta$ types still holds. 

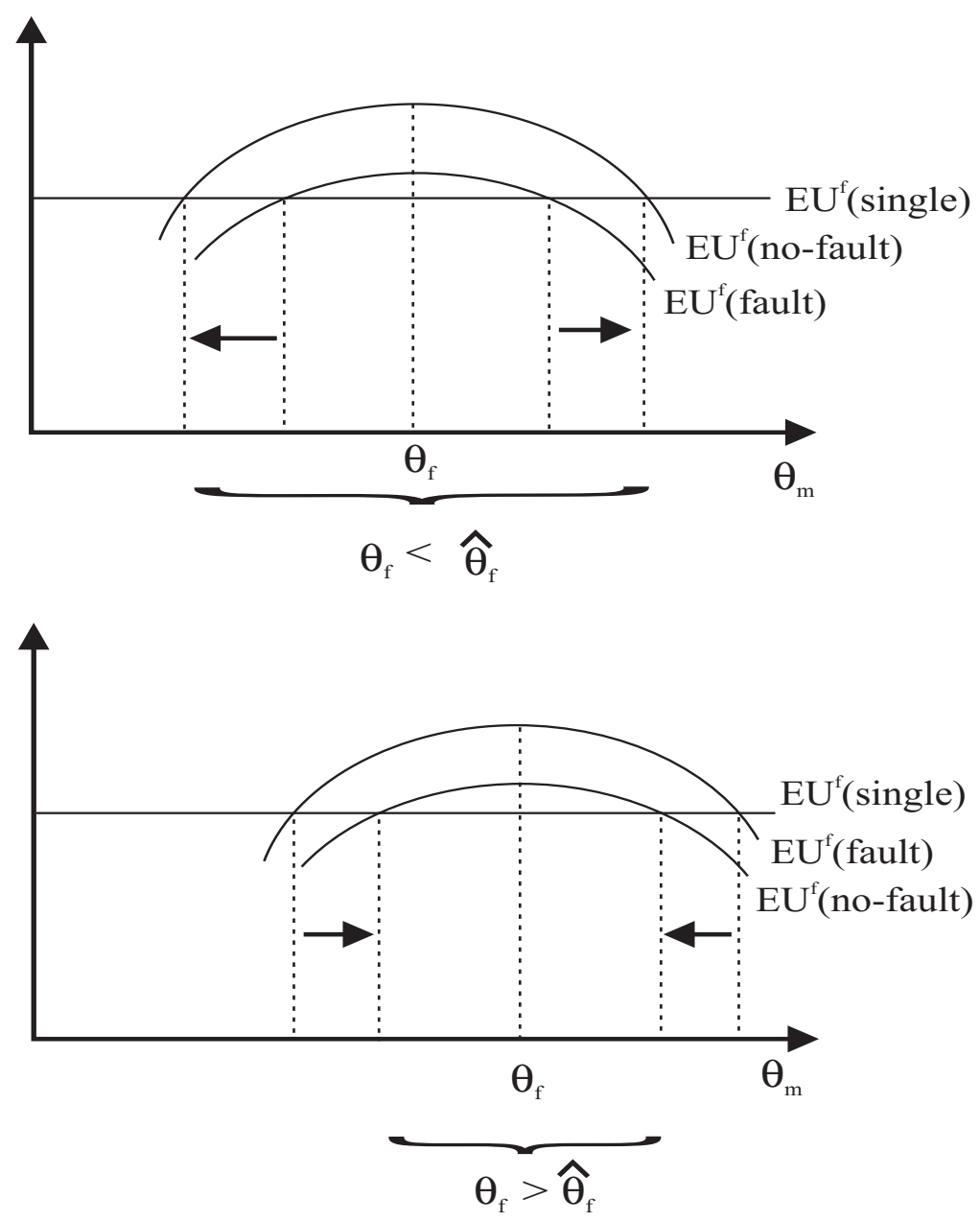

Figure 2

and married older $\left(\theta<\hat{\theta}_{f}\right)$ marry a little earlier. ${ }^{10}$ Thus, no-fault divorce brings along with it a reduction in the spread of marriage ages. This conclusion depends on the premise that the change in search behavior brought about by changes in the divorce law does not swamp the initial differences in marriage ages. For example, individuals who marry late under fault do not marry younger than everyone else after the switch to no-fault. In our model, there is no such "overshooting." When

10 Bougheas and Georgellis (1999) have a model in which a lower cost of divorce leads to greater marriage formation. In our model, a switch to no-fault divorce increases the cost for committed types if the marriage turns sour. The change in legal regime leads to lower marriage formation for these types. 
the parameter $k$ is sufficiently large, the range of acceptable mates (i.e., $\bar{\theta}_{m}-\underline{\theta}_{m}$ ) is increasing in $\theta_{f}$ under both regimes. Therefore, although the high- $\theta$ types marry later after the switch, they still marry earlier than do the low- $\theta$ types under no-fault.

The model's prediction regarding the mean age at marriage is more ambiguous. Changes in the mean age of marriage reveal changes in the total amount of search in the marriage market. The change in the mean marriage age may be small because of offsetting changes on both sides. When the population comprises both high and low $\theta$ people, we cannot make a population-level welfare statement about the whether or not no-fault divorce helps or hurts people. Under the model, no-fault hurts people with high $\theta$ because they have to search longer for a marital partner, but it helps low $\theta$ people because they do not have to search as long for a marital partner. In a heterogenous population, the legal change seems unlikely to help everyone. If we assume that the cost of marital search is the same for all people, and is independent of the length of marital search, then the sum or average change in marital search effort is a rough welfare indicator. Thus, if the model is plausible and its predictions on the spread of marriage age are met, we may take the average change in age at first marriage as suggestive of the overall welfare effect of the change in divorce law. ${ }^{11}$

11 Finally, this model allows one to make predictions about the differential effect of the change in law on men and women if one is willing to make assumptions about the difference in their propensity to experience marital shocks. Consider, for example, the comparative statics of a change in $p_{f}$ on the critical type $\hat{\theta}_{f}$. From equation (8),

$$
\frac{\partial \Delta^{f}}{\partial p_{f}}=\left(1-p_{m}\right)\left[-2 \theta_{f}-\left(1-\left(\theta_{f}-\theta_{m}\right)^{2}\right)\right]-p_{m}\left[2-2 \theta_{f}+\left(\theta_{f}-\theta_{m}\right)^{2}\right]<0 .
$$

Thus, an increase in $p_{f}$ shifts down the $\Delta^{f}$ curve. Since $\Delta^{f}$ is downward-sloping, this means that the critical point $\hat{\theta}_{f}$ at which $\Delta^{f}=0$ shifts to the left. This establishes that $\partial \hat{\theta}_{f} / \partial p_{f}<0$. Similarly, one can show that $\partial \hat{\theta}_{f} / \partial p_{m}>0$. The comparative statics for men are of course parallel; i.e., $\partial \hat{\theta}_{m} / \partial p_{m}<0$ and $\partial \hat{\theta}_{m} / \partial p_{f}>0$. If, as it is commonly assumed, $p_{f}>p_{m}$ (women are less likely to experience marital shocks than men), this analysis suggests that the critical types for the two sexes satisfy $\hat{\theta}_{f}<\hat{\theta}_{m}$. The group of women who are hurt by no-fault divorce $\left(\theta_{f}>\hat{\theta}_{f}\right)$ is proportionately larger than the group of men who are hurt by no-fault divorce $\left(\theta_{m}>\hat{\theta}_{f}\right)$. According to our model, this implies that proportionately more women than men would delay their marriage following the change in divorce law. This result is consistent with our empirical findings. See Figure 3 below. 


\section{The Data}

We take the log of age at first marriage as our indicator of search intensity and its standard deviation as our indicator of its spread, and assess whether or not the standard deviation of log marriage age is smaller in no-fault states and years than in fault states and years. ${ }^{12}$ Our data are samples of marriage records collected by state governments and held by the National Center for Health Statistics. We use all records for first marriages of men and women from 1970 to 1995 for the 932 state-years in which first marriage indicators are available and in which there were no separation requirements for divorce. ${ }^{13}$ For some states, which we will call "switchers", the divorce law switched from fault to no-fault during this period. For all other states, the divorce law did not change during the period. We are left with $6,251,877$ individual records for females and 5,925,396 individual records for males.

Our identification strategy uses the six million records available for men and women to compute state-year distributional statistics (e.g., means, standard deviations, and quantiles) of the log of age at first marriage, and to run regressions of these distributional statistics on the divorce law, and year and state fixed effects. We use the timing of the switch to no-fault in different switcher states to identify the effect of no-fault divorce on the distribution of log age at first marriage.

There is some ambiguity in the phrase "no-fault divorce." Hence, in Table 2, we provide a list of the years in which states switched from fault to no-fault under three different definitions of no-fault. In the U.S. each state has it own divorce law, and although many are virtually identical to each other, there is considerable

12 We use the standard deviation of logs because marriage age distributions look roughly lognormal. In addition we examine quantiles of the distributions, which does not impose structure on the marriage age distribution.

13 We examine first marriages because individuals marry at an older age on their second and third marriages, which bias the results. Selecting on first marriages reduced the sample to 41 states plus the District of Columbia. The left-out states are Arkansas, Arizona, North Dakota, Oklahoma, Texas, New Mexico, Utah, Nevada, and Washington. Separation requirements are hard to classify as either fault or no-fault. On the one hand, a separation requirement makes divorce difficult and costly, but on the other hand, separation is essentially a unilateral decision. 
variation. Some states add a no-fault provision to existing faults for the grounds for divorce. Other states add a no-fault provision to the statutes on grounds and property settlement. Still others may only have a separation clause allowing for divorce and this separation clause may or may not require a property agreement. ${ }^{14}$ Law and economics scholars have come up with two methods of dealing with this ambiguity. The first is to consider the unilateral characteristics of the change in divorce law. Simply put, does the law allow one party to divorce without the consent of the other? This is a weak notion of no-fault because it ignores the cost of divorcing. The second approach considers a law no-fault if it is unilateral and if fault is not considered in property settlements, alimony, or other aspects of the divorce.

In this paper we use both notions of no-fault to assess the model and to measure the marginal effect of increasing the strength of the law. The first we call NO-FAULT, denoting law which permits any form of unilateral divorce, following the classification used by Friedberg (1998), Table 1, column (1). ${ }^{15}$ The second we call "strong no-fault," denoting law which is no-fault and for which fault does not enter certain aspects of the cost of divorce. We have two classifications of states for strong no-fault: the first again comes from Friedberg (1998), Table 1, column (3); the second comes from Brinig and Buckley (1998), Table 1. We will call these variables FRIEDBERG STRONG NO-FAULT, and BRINIG \& BUCKLEY STRONG NO-FAULT. Almost all states covered by the Brinig \& Buckley strong no-fault classification are covered by the Friedberg strong no-fault classification. ${ }^{16}$ The key

14 There is also ambiguity in the timing of the law depending on whether one uses timing of legislation or court decisions. This is apparent in Table 2 where the column under "Year" refers to the timing according to Friedberg (1998), who used legislation. When this timing is inconsistent with the timing used by Brinig and Buckley (1998), who used court decisions, we note it in the relevant column.

15 Friedberg's column (1) contains five inconsistencies with her column (3), which we correct based on other sources. We code Delaware, Illinois, Missouri, and Wisconsin as weak no-fault states. For Oregon, we code the switch to no-fault occuring in 1971, not 1973.

16 There are two disagreements: Delaware and Florida. 
difference between these two definitions is that Friedberg strong no-fault requires that fault does not enter property settlements, but Brinig \& Buckley strong no-fault requires in addition that fault does not enter alimony.

Table 3 provides the definitions of variables used in the paper. Table 4 provides summary statistics about age at first marriage for all state-years and for those states where the law was either always fault or always no-fault. For women, the standard deviation of age at first marriage in the 207 always fault state-years had an average of 5.64 whereas in the 85 always no-fault state-years the standard deviation had an average of 4.62 - an approximate difference of $20 \%$. For men, in the always fault state-years the standard deviation had an average of 6.10 , whereas in the always no-fault state-years the standard deviation had an average of 5.32 - an approximate difference of $13 \%$. These differences in the standard deviation of age at first marriage in fault versus no-fault regimes are fairly large. In contrast, the mean age at first marriage are very similar between fault and no-fault state-years. Table 4 also reports the summary statistics for the log age at first marriage (which is used as a dependent variable in the regressions), and the same patterns are seen.

Regressions presented below use log-age as the left-hand side variable to indicate the intensity of marital search. We use the logarithmic transformation because age at first marriage distributions are right-hand skewed. Comparison of the alwaysfault with the always-no-fault states as in Tables 3 and 4 may be misleading if these states differ in important (perhaps cultural) ways that might affect marital search. It is better to examine how a change in divorce law affects marriage age distributions within states. To this end, the regressions below use the subsample of 615 stateyears for "switcher" states and include both state and year fixed effects. That we use only "switcher" states means that no cross-sectional variation is necessary to identify our effects. That we include state fixed effects means that any timeindependent effects on marital search which vary by state — such as state-specific cultural norms - will not pollute our estimate. That we include year effects means that any state-independent effects on marital search which vary by year — such 
as an overall social trend towards later marriage — will not pollute our estimates. Our estimates of the effect of divorce law on marriage age distributions are thus identified by differences in the timing of divorce law changes across states.

\section{Results}

\subsection{The Mean Age at First Marriage}

Table 5 gives selected coefficients from regressions in which the left hand side variable is the mean of the log age at first marriage in a state-year and the right hand side variables are combinations of divorce law variables plus state and year fixed effects. We run separate regressions for men and women - t-statistics are given in parentheses underneath the coefficients.

Regression (1) shows that no-fault divorce pushes up the mean log age at first marriage for women by 0.003 - or about 1 month. In Regressions (2) to (4), the marginal effects of either or both strong no-fault definitions are shown. In all three regressions, the effect of no-fault on the mean log age at first marriage for women is statistically significant and positive, and in some cases amounts to as much as 7 months. Strong no-fault has a small positive effect with the Brinig \& Buckley definition, and a small positive effect with the Friedberg definition.

Regressions (5) to (8) show similar results for men. Men in no-fault stateyears also marry anywhere from one month to 5 months later than men in fault state-years, depending on the legal regime. This point estimate is enhanced by the inclusion of both strong no-fault variables, which are statistically significant with the Brinig \& Buckley definition. Regressions (1) to (8) show that no-fault divorce is correlated with later marriage for both men and women. Given the model above,

this suggests that per-person marital search time is higher under no-fault. For both men and women, the mean increased with the introduction of no-fault divorce law. However, these increases were quite small, amounting to a few months. 


\subsection{The Standard Deviation of the Age at First Marriage}

Our model made no predictions regarding the mean age at first marriage since this depends on the unknown distribution of $\theta$. However, our prediction that the distribution of first marriage ages should compress is testable. Table 6 containing regressions (9) to (16) shows results for men and women where the left hand side variable is the standard deviation of the log age at first marriage in a state-year. The coefficients from these regressions are interpreted as the absolute changes in the standard deviation in logs. Hence they are comparable to the summary statistics on the bottom half of Table 4. Regression (9) shows that no-fault divorce pushes down the standard deviation of the log age at first marriage for women by 0.002 . Given that the standard deviation of log age for all years is 0.19 , this amounts to a $1.2 \%$ fall in the standard deviation. Inclusion of strong no-fault variables in the model increases this effect to as much as 0.011 , which is a fall of $4.7 \%$.

Regressions (13) to (16) show results for men. Regression (13) shows that nofault divorce lowers the standard deviation of the log age at first marriage for men by 0.002 , or by approximately $1.2 \%$. Inclusion of strong no-fault variables again magnifies the effect. In regression (14), adding Friedberg strong no-fault divorce lowers the standard deviation of the log by 0.005 (or, $2.5 \%$ ), and from regression (15) adding the Brinig \& Buckley strong no-fault lowers it by 0.011 (or 5.6\%) in total. The main result in Table 6 is that the data are consistent with the hypothesis that no-fault divorce reduces the spread of the age at first marriage for both women and men. However, table 6 shows evidence of a small and marginally significant negative effect on dispersion of no-fault divorce. The weakness of this finding could be driven by one of two things: our measures of either no-fault divorce or our measure of spread may be imperfect. With respect to the measure of no-fault, Brinig \& Buckley's measure is associated with a larger and stronger decreasing spread. This suggests that this measure is more strongly correlated with divorce costs than the other measures - this is, in fact the argument they make for their definition. With respect to the measure of spread, the standard deviation of the 
logs gives strong weight to variation in the tails of the distribution compared to other measures of spread, we now take this up in the next section.

\subsection{Percentile and Inter-quartile Regressions}

A non-parametric approach to looking at spread is to ask how no-fault affects each and every percentile of the marriage age distribution. To this end we ran regressions where the left hand side variable is the $k^{\text {th }}$ percentile of the marriage age distribution by state and year for each $k=5,10 \ldots 95{ }^{17}$ The first percentile regression uses as the left hand side variable the first percentile cutoff of the age distribution in a state-year as the LHS variable. The second regression uses as the LHS the second percentile cutoff, and so on. The effect of no-fault in these regressions is depicted graphically in Figure 3. As our model predicts, those who married youngest increased their ages at marriage with the introduction of no fault, and those who married oldest decreased their ages at marriage. In addition, there is an almost monotonically decreasing function relating the effect of no fault on age at first marriage to the percentiles of the marriage age distribution. For men below the $80^{\text {th }}$ percentile there was an increase in age at marriage, but for all other men there was a decrease in age at marriage. For women below the $85^{\text {th }}$ percentile there was an increased in age at marriage. The nearly monotonic relationship is quite striking. These regressions can be interpreted as revealing information on $\theta$. They suggest that the U.S. population is dominated by high $\theta$ types.

Figure 3 also shows an increase in standard errors for the very low and high percentiles. Furthermore, the negative monotonic prediction is clearly strongest for the inter-quintile range (the difference between the 80th and 20th percentiles). This motivates the regressions in Table 7 , where the dependent variable is the log of the $80^{\text {th }}$ percentile minus the log of the $20^{\text {th }}$ percentile. Regressions (17) to (20) show the results for women, and regressions (21) to (24) show the results for men. As might be expected considering Figure 3, these results show a considerably stronger

17 Since there are 800 regressions, we do not report them here, but they are available on request. 
effect. For women the reduction in the standard deviation range from $4.7 \%$ to $13 \%$, while for men the reduction ranges from $3 \%$ to $9.2 \%$.

\section{Conclusion}

Our model predicts that when divorce law switches to no-fault, some members of the population will search more intensively for a marital partner and other members of the population will search less intensively. In particular, those who needed to search little under a fault regime have to search more under no-fault, and those who needed to search greatly under a fault regime have to search less under no-fault. Thus, over the transition from fault to no-fault, the dispersion of search intensity should decline and there should be a compression in the distribution of age at first marriage. The empirical work presented in this paper demonstrates that the introduction of no-fault divorce was actually associated with such a compression. The size of the compression seems to be of the same order of magnitude as what is found for the effect of no-fault on divorce rates. Taking the results on the spread of marriage age as corroboration for our model, our findings have an interesting implication. Under the model, changes in the mean age at marriage indicate changes in per-person marital search costs. We find the mean age of marriage increased by 1 to 2 months, suggesting that total search time increased by a small amount. However, this was not due to the entire population searching a little bit longer. Rather, the fairly large decrease in the dispersion of age at first marriage suggests that some people had to search much longer while others had to search much less, with the incidence of changes in marital search tilted slightly towards those who searched longer. 


\section{References}

Allen, Douglas W. "No-Fault Divorce and the Divorce Rate: Its History, Effect, and Implications" in Douglas W. Allen and John Richards (eds.) It Takes Two: The Family in Law and Finance (Toronto: C.D. Howe Institute, 1999).

Bougheas, Spiros, and Yannis Georgellis. "The Effect of Divorce Costs on Marriage Formation and Dissolution." Journal of Population Economics 12, August 1999: 489-498.

Brinig, Margaret, and Frank Buckley. "No-Fault Laws and At-Fault People." International Review of Law and Economics 18 September 1998: 325-340.

Friedberg, Leora. "Did Unilateral Divorce Raise Divorce Rates?: Evidence From Panel Data." American Economic Review 88(3) June 1998: 608-627.

Keeley, Michael C. "The Economics of Family Formation." Economic Inquiry 15 April 1977: 238-250.

Parkman, Allen M. No-Fault Divorce: What Went Wrong? (Boulder: Westview Press, 1992).

Wolfers, Justin. "Did Unilateral Divorce Laws Raise Divorce Rates? A Reconciliation and New Results." (NBER Working Paper No. 10014), October 2003. 


\section{Appendix: $\theta$ and the Range of Acceptable Mates}

Our paper assumes that higher $\theta$ types have a greater chance of finding an acceptable mate. To show this, note that the critical values $\underline{\theta}_{m}$ and $\bar{\theta}_{m}$ are solutions to the equation, $E U^{f}$ (fault) $-S=0$, where $S$ denotes the expected utility from remaining single. This is a quadratic equation in $\theta_{m}$ and its roots are given by

$\theta_{f} \pm \sqrt{\frac{p_{f} p_{m} k \theta_{f}+p_{f}\left(1-p_{m}\right) \theta_{f}+\left(1-p_{f}\right) p_{m}\left(\theta_{f}-1\right)+\left(1-p_{f}\right)\left(1-p_{m}\right)\left(1-\theta_{f}\right)+p_{f}-S}{p_{f} p_{m}+p_{f}\left(1-p_{m}\right)+\left(1-p_{f}\right) p_{m}}}$.

If male types are uniformly distributed across the population, the probability of finding an acceptable mate for a woman with type $\theta_{f}$ is proportional to

$$
\bar{\theta}_{m}-\underline{\theta}_{m}=2 \sqrt{\frac{p_{f} p_{m} k \theta_{f}+p_{f}\left(1-p_{m}\right) \theta_{f}+\left(1-p_{f}\right) p_{m}\left(\theta_{f}-1\right)+\left(1-p_{f}\right)\left(1-p_{m}\right)\left(1-\theta_{f}\right)+p_{f}-S}{p_{f} p_{m}+p_{f}\left(1-p_{m}\right)+\left(1-p_{f}\right) p_{m}}} .
$$

This expression is increasing in $\theta_{f}$ if and only if

$$
p_{f} p_{m} k+p_{f}\left(1-p_{m}\right)+\left(1-p_{f}\right) p_{m}-\left(1-p_{f}\right)\left(1-p_{m}\right)>0 \text {. }
$$

When $p_{f}=p_{m}=p$, condition (5) reduces to

$$
k>(1-p)(1-3 p) / p^{2}
$$

For $k=2$, inequality (6) is satisfied for all $p>0.27$. Under fault law, $p>0.27$ implies a divorce rate of lower than 0.47 , which is empirically plausible. For higher values of $k$, the restriction on $p$ is even less stringent. Under reasonable assumptions, therefore, the probability of finding an acceptable mate is higher for those who are more committed to marriage. 
TABLE 2: No-Fault States

\begin{tabular}{|c|c|c|c|c|c|c|c|c|c|}
\hline STATE & $\mathrm{NF}^{1}$ & F-SNF ${ }^{2}$ & BB-SNF ${ }^{3}$ & Year & STATE & $\mathrm{NF}$ & F-SNF & BB-SNF & Year \\
\hline Alabama & 1 & 0 & 0 & 71 & Nevada & 1 & 1 & 0 & 73 \\
\hline Alaska & 1 & 1 & 0 & 68 & New Hampshire & 1 & 0 & 0 & 71 \\
\hline Arizona & 1 & 1 & 1,74 & 73 & New Jersey & 0 & 0 & 0 & - \\
\hline Arkansas & 0 & 0 & 0 & - & New Mexico & 1 & 1 & 0 & 73 \\
\hline California & 1 & 1 & 1,69 & 70 & New York & 0 & 0 & 0 & - \\
\hline Colorado & 1 & 1 & 1 & 71 & North Carolina & 0 & 0 & 0 & - \\
\hline Connecticut & 1 & 0 & 0 & 73 & North Dakota & 1 & 0 & 0 & 71 \\
\hline Delaware & 1 & 0 & 1 & 79 & Ohio & 0 & 0 & 0 & - \\
\hline $\mathrm{DC}$ & 0 & 0 & 0 & - & Oklahoma & 1 & 1 & 1,75 & 68 \\
\hline Florida & 1 & 0 & 1,78 & 71 & Oregon & 1 & 1 & 1 & 71 \\
\hline Georgia & 1 & 0 & 0 & 73 & Pennsylvania & 0 & 0 & 0 & - \\
\hline Hawaii & 1 & 1 & 1,72 & 73 & Puerto Rico & 0 & 0 & 0 & - \\
\hline Idaho & 1 & 0 & 0 & 71 & Rhode Island & 1 & 0 & 0 & 76 \\
\hline Illinois & 1 & 1 & 1 & 84 & South Carolina & 0 & 0 & 0 & - \\
\hline Indiana & 1 & 1 & 1 & 73 & South Dakota & 1 & 0 & 0 & 85 \\
\hline Iowa & 1 & 1 & 1,71 & 70 & Tennessee & 0 & 0 & 0 & - \\
\hline Kansas & 1 & 0 & 0 & 69 & Texas & 1 & 0 & 0 & 74 \\
\hline Kentucky & 1 & 1,87 & 1,87 & 72 & Utah & 0 & 0 & 0 & - \\
\hline Louisiana & 0 & 0 & 0 & - & Vermont & 0 & 0 & 0 & - \\
\hline Maine & 1 & 1 & 0 & 73 & Washington & 1 & 1 & 1 & 73 \\
\hline Maryland & 0 & 0 & 0 & - & Virgin Islands & 1 & 1 & 1 & 73 \\
\hline Massachusetts & 1 & 0 & 0 & 75 & Virginia & 0 & 0 & 0 & - \\
\hline Michigan & 1 & 0 & 0 & 72 & West Virginia & 0 & 0 & 0 & - \\
\hline Minnesota & 1 & 1 & 1 & 74 & Wisconsin & 1 & 1 & 1 & 77 \\
\hline Mississippi & 0 & 0 & 0 & - & Wyoming & 1 & 0 & 0 & 77 \\
\hline Missouri & 1 & 1 & 0 & 73 & & & & & \\
\hline Montana & 1 & 1 & 1 & 75 & & & & & \\
\hline Nebraska & 1 & 1 & 1 & 72 & & & & & \\
\hline
\end{tabular}

$1=$ No Fault.

$2=$ Friedberg's Strong No Fault.

$3=$ Brinig and Buckley's Strong No Fault. 
TABLE 3: Variable Definitions

\begin{tabular}{|c|c|c|}
\hline Variable & & Definition \\
\hline No Fault & $=$ & $\begin{array}{l}1 \text { if state has unilateral divorce. } \\
\text { Taken from Friedberg 1998, Table 1, Column (1). }\end{array}$ \\
\hline Friedberg's & & \\
\hline STRONG No Fault & $=$ & $\begin{array}{l}1 \text { if state does not include fault in grounds and property settlement. } \\
\text { Taken from Friedberg 1998, Table 1, Colomn (3). }\end{array}$ \\
\hline Brinig and Buckley's & & \\
\hline STRONG No Fault & $=$ & $\begin{array}{l}1 \text { if state if fault is completely irrelevant. } \\
\text { Taken from Brinig and Buckley 1998, Table } 1 .\end{array}$ \\
\hline YEAR EFFECTS & $=$ & series of dummy variables for each year: 1970-1995. \\
\hline STATE EFFECTS & $=$ & series of dummy variables for each state. \\
\hline SEPARATION & $=$ & $\begin{array}{l}1 \text { state uses a length of separation for no-fault. } \\
\text { Based on Friedberg, 1998, Table 1, Column (2). }\end{array}$ \\
\hline
\end{tabular}


TABLE 4: Summary Statistics

Age at First Marriage

\begin{tabular}{lcccc} 
LAW & State-Years & Mean & SD & Difference (SD) \\
\hline FEMALES & & & & \\
$\quad$ All Years & 932 & 22.69 & 4.97 & \\
Always Fault & 207 & 23.04 & 5.64 & -1.02 \\
Always No-Fault & 85 & 22.39 & 4.62 & \\
& & & & \\
MALES & & & & \\
$\quad$ All Years & 932 & 24.78 & 5.61 & \\
Always Fault & 207 & 25.01 & 6.10 & -0.78 \\
Always No-Fault & 85 & 24.59 & 5.32 & \\
& & & & \\
\hline
\end{tabular}

Log Age at First Marriage

\begin{tabular}{lcccc} 
LAW & State-Years & Mean & SD & Difference (SD) \\
\hline FEMALES & & & & \\
$\quad$ All Years & 932 & 3.099 & 0.190 & \\
$\quad$ Always Fault & 207 & 3.109 & 0.207 & \\
Always No-Fault & 85 & 3.088 & 0.182 & -0.026 \\
& & & & \\
MALES & & & & \\
$\quad$ All Years & 932 & 3.186 & 0.195 & \\
Always Fault & 207 & 3.192 & 0.206 & -0.017 \\
Always No-Fault & 85 & 3.181 & 0.189 & \\
& & & & \\
\hline
\end{tabular}


TABLE 5: OLS Regression

Dependent Variable $=$ Mean Log Marriage Age, $N=615$

Women

\begin{tabular}{lllll} 
Variable & $(1)$ & $(2)$ & $(3)$ & $(4)$ \\
\hline No Fault & $0.003^{*}$ & $0.006^{*}$ & $0.003^{*}$ & $0.007^{*}$ \\
& $(3.39)$ & $(3.57)$ & $(2.54)$ & $(3.77)$ \\
Friedberg & & & & \\
$\quad$ Strong No Fault & & 0.002 & & 0.005 \\
& & $(2.26)$ & & $(1.72)$ \\
Brinig and Buckley & & & & \\
$\quad$ Strong No Fault & & & $0.003^{*}$ & $0.014^{*}$ \\
& & & $(3.49)$ & $(4.56)$ \\
\end{tabular}

Men

\begin{tabular}{lllll} 
Variable & $(5)$ & $(6)$ & $(7)$ & $(8)$ \\
\hline No Fault & $0.002^{*}$ & $0.007^{*}$ & $0.003^{*}$ & $0.007^{*}$ \\
& $(2.23)$ & $(4.26)$ & $(3.04)$ & $(4.29)$ \\
Friedberg & & & & \\
$\quad$ Strong No Fault & & 0.006 & & 0.004 \\
& & $(0.59)$ & & $(1.00)$ \\
Brinig and Buckley & & & & \\
$\quad$ Strong No Fault & & & 0.001 & $0.008^{*}$ \\
& & & $(1.24)$ & $(3.65)$
\end{tabular}

t-statistics are reported in parentheses underneath coefficient estimates.

Each regression has 615 state-year observations of the mean age at first marriage.

Each regression has year and state fixed effects (not reported).

* significant at the $5 \%$ level in a two tailed test. 
TABLE 6: OLS Regression

Dependent Variable $=$ Standard Deviation of Log Marriage Age, N=932

Women

\begin{tabular}{lllll} 
Variable & $(9)$ & $(10)$ & $(11)$ & $(12)$ \\
\hline No Fault & $-0.002^{*}$ & -0.002 & -0.007 & -0.002 \\
& $(-1.74)$ & $(-1.64)$ & $(-0.59)$ & $(-1.79)$ \\
Friedberg & & & & \\
$\quad$ Strong No Fault & & -0.002 & & 0.002 \\
& & $(-1.49)$ & & $(1.15)$ \\
Brinig and Buckley & & & & \\
$\quad$ Strong No Fault & & & $-0.004^{*}$ & $-0.009^{*}$ \\
& & & $(-3.13)$ & $(-4.64)$ \\
\hline
\end{tabular}

Men

\begin{tabular}{lllll} 
Variable & $(13)$ & $(14)$ & $(15)$ & $(16)$ \\
\hline No Fault & -0.002 & -0.002 & -0.007 & -0.002 \\
& $(-1.61)$ & $(-1.55)$ & $(-0.59)$ & $(-1.68)$ \\
Friedberg & & & & \\
$\quad$ Strong No Fault & & -0.003 & & 0.004 \\
& & $(-1.36)$ & & $(1.77)$ \\
Brinig and Buckley & & & $-0.004^{*}$ & $-0.009^{*}$ \\
$\quad$ Strong No Fault & & & $(-3.13)$ & $(-4.51)$
\end{tabular}

t-statistics are reported in parentheses underneath coefficient estimates.

Each regression has 615 state-year observations of the standard deviation of the log age at first marriage.

Each regression has year and state fixed effects (not reported).

* significant at the $5 \%$ level in a two tailed test. 
TABLE 7: OLS Regression

Dependent Variable $=$ Log Interquartile Range, $N=615$

Women

\begin{tabular}{lllll} 
Variable & $(17)$ & $(18)$ & $(19)$ & $(20)$ \\
\hline No Fault & $-0.009^{*}$ & $-0.012^{*}$ & $-0.016^{*}$ & $-0.011^{*}$ \\
& $(-3.94)$ & $(-3.98)$ & $(-5.35)$ & $(-3.78)$ \\
Friedberg & & & & \\
$\quad$ Strong No Fault & & $-0.008^{*}$ & & 0.003 \\
& & $(-3.13)$ & & $(0.63)$ \\
Brinig and Buckley & & & & \\
$\quad$ Strong No Fault & & & $-0.009^{*}$ & -0.006 \\
& & & $(-2.80)$ & $(-1.70)$ \\
\hline
\end{tabular}

Men

\begin{tabular}{lllll} 
Variable & $(21)$ & $(22)$ & $(23)$ & $(24)$ \\
\hline No Fault & $-0.006^{*}$ & $-0.007^{*}$ & $-0.008^{*}$ & $-0.007^{*}$ \\
& $(-3.39)$ & $(-2.54)$ & $(-3.15)$ & $(-2.51)$ \\
Friedberg & & & & \\
$\quad$ Strong No Fault & & $-0.006^{*}$ & & -0.002 \\
& & $(-2.97)$ & & $(-0.60)$ \\
Brinig and Buckley & & & & \\
$\quad$ Strong No Fault & & & $-0.010^{*}$ & $0.010^{*}$ \\
& & & $(-3.65)$ & $(-3.04)$
\end{tabular}

t-statistics are reported in parentheses underneath coefficient estimates.

Each regression has 615 state-year observations of the mean age at first marriage.

Each regression has year and state fixed effects (not reported).

* significant at the $5 \%$ level in a two tailed test. 

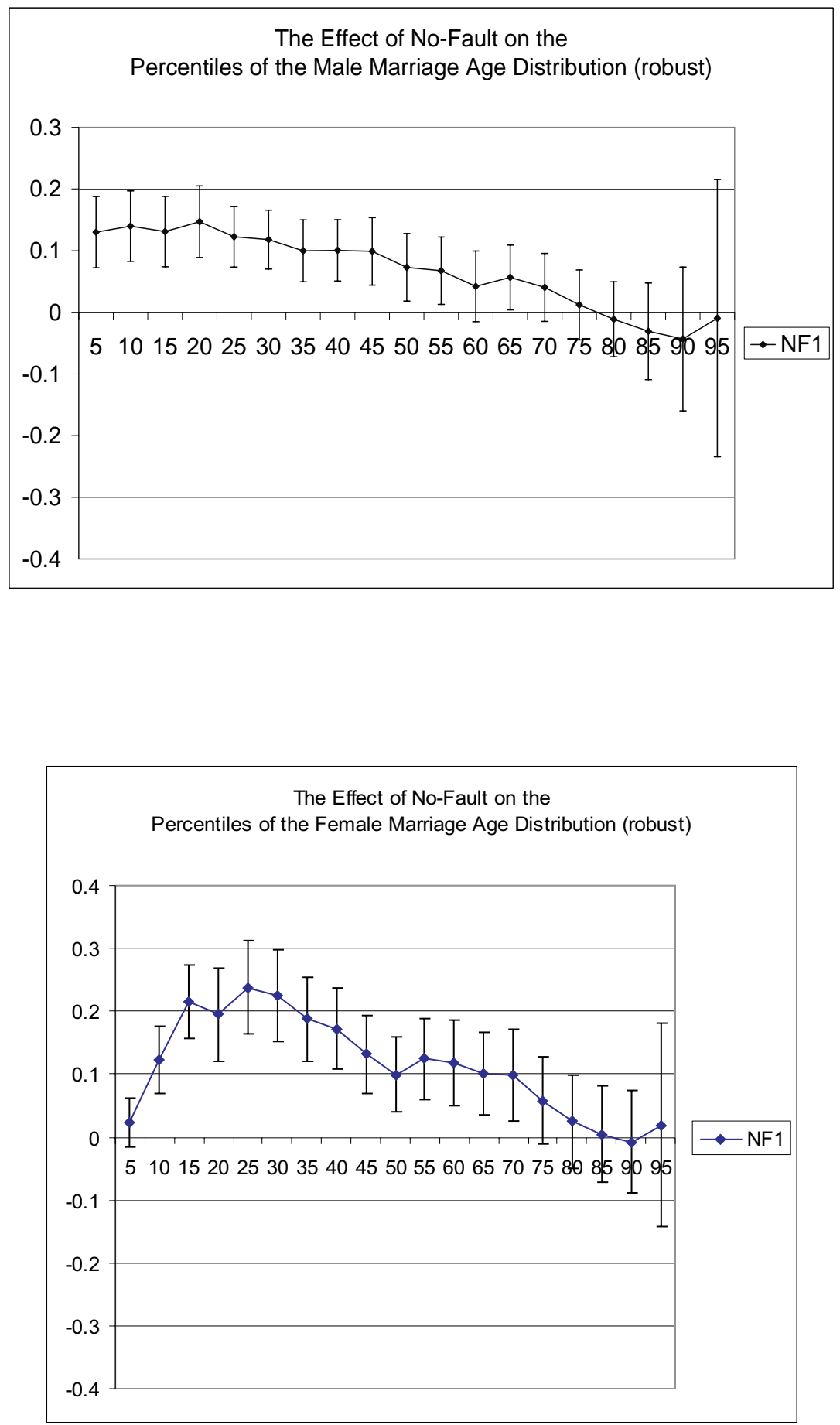

Figure 3 
